\title{
A Specific and Reliable Test for Charcot Neuropathy is Still Missing
}

\author{
Ulrich Illgner*1, Armstrong DG ${ }^{2}$, Slepian $\mathbf{M}^{3}$ and Krenn $\mathbf{V}^{4}$ \\ ${ }^{1}$ Seintsch and Illgner, Gemeinschaftsklinikum Mittelrhein, Germany \\ ${ }^{2}$ SALSA University Hospital of Tucson, USA \\ ${ }^{3}$ Department Head of Biomedical Engeneering, University Hospital of Tucson, USA \\ ${ }^{4}$ Medical Center for Histology, Cytology and Molecular Diagnostic, Germany \\ Received: February 23, 2018; Published: March 05, 2018
}

*Corresponding author: Ulrich Illgner, Seintsch and Illgner, Privat Doctors Office, Gemeinschaftsklinikum Mittelrhein, Finkenschlag 5, 56077 Koblenz, Germany, Tel: 00491606319110; Email: ulrich_illgner@web.de

\begin{abstract}
Background: Charcot Neuropathy is a severe complication of patients with neuropathy mostly seen in the foot, but it can also appear in the knee or hand. Not only diabetic patients are involved. $\mathrm{CN}$ can lead to a complete collapse of the foot with subsequent ulceration and infection. The mechanism of this episode-like breakdown has not been understood so far. $\mathrm{CN}$ still remains mainly a clinical diagnosis depended on clinical experience because there is still no reliable and specific test even though imaging has improved. X-rays represent the traditional way to diagnose $\mathrm{CN}$ according to the classification of Eichenholtz of 1967. But at the time these alterations become visible, the bone is already damaged. Therefore Shiabata introduced the MRI as Stage 0 into this existing classification. New approaches using CT or PET/CT have been published.
\end{abstract}

But these procedures are expensive, not everywhere available, do not show the situation of foot while weight-bearing and still often lead to wrong or unclear diagnoses. Usually it takes days to weeks until MRT or PET/CT can be performed. Especially to distinguish between infection and CN can remain difficult. There is no marker in blood sampling for diagnosis. New research indicates a possible role of changes in mRNA expression of collagens in the pathomechanism, which might be used in the future for histopathological tests. It would be important to create reliable and reproducible testing standards and signs unique for CN.

Conclusion: It is important to diagnose patients with Charcot Neuroarthropathy in early stages to prevent destruction and ulceration by simple procedures such as supply with insoles and shoes. Understanding the pathological mechanism of $\mathrm{CN}$ and finding new criteria for new test are necessary.

Keywords: Charcot Neuropathy; Test; MRI; Eichenholtz; Pathology; Collagen

\section{Introduction}

\section{Background}

Charcot described the episode-like destruction of bones and joints more than 150 years ago but still the pathological mechanism and its histological correlates have not been found. After the neurotrophological or "French" theory and the microtraumatic or "German" theory opposed each other for 100 years, Jeffcoate postulated a new theory stating that the activation of the RANKL/ OPG systems causes CN in 2005 [1]. In blood samples proinflammatory cytocines could be shown but histological correlates for this theory have not been found so far and there is still no reliable and specific test. $\mathrm{CN}$ of the foot represent a severe complication of neuropathic feet that can lead to ulceration with subsequent infection. Infected can cause serious damage to the foot or cause or lead even to a life-threatening sepsis.

Most patients with $\mathrm{CN}$ suffer from diabetes and the rate seems to be rising $[2,3]$. It is important to mention that $\mathrm{CN}$ can be due to any kind of neuropathy e.g. rheumatic diseases, alcohol abuse, toxicity $[3,4]$. CN is not only seen in feet but in knees and hands as well $[5,6]$. It is necessary to understand the exact pathological mechanism and correlates of $\mathrm{CN}$ to be able to find a test and further on a treatment. 
Especially early stages of CN must be detected before bone and joints are destroyed with all the complications following and to prevent surgery often including (partial-) amputation.

\section{Clinical Signs}

The clinical signs of $\mathrm{CN}$ depend on the stage. As long as no major damage has happened, the foot can clinically appear normal, especially in Eichenholtz stages 2 and 3. In acute stages usually the foot is red, swollen and can be unstable, typical is the absence of pain [3]. in most cases acute stages occure unilateral in contrast to the mostly bilateral neuropathy. Minor (repetitive?) trauma seems to trigger this destructive process [3]. In many cases there is a difference in temperature, so thermography can be used for diagnosis as well, even though this is not standardized or specific. Blood flow is many cases increased so that the pulse is well palpable, but PVD can be present in the same patient with multiple co-morbidities in most of the cases. There are no specific clinical signs so that finding the diagnosis can be difficult and is related to the experience of the physician. Wrong diagnoses e.g. thrombosis or infection still are common. Often it still takes months to years for many patients until the diagnosis of $\mathrm{CN}$ is found.

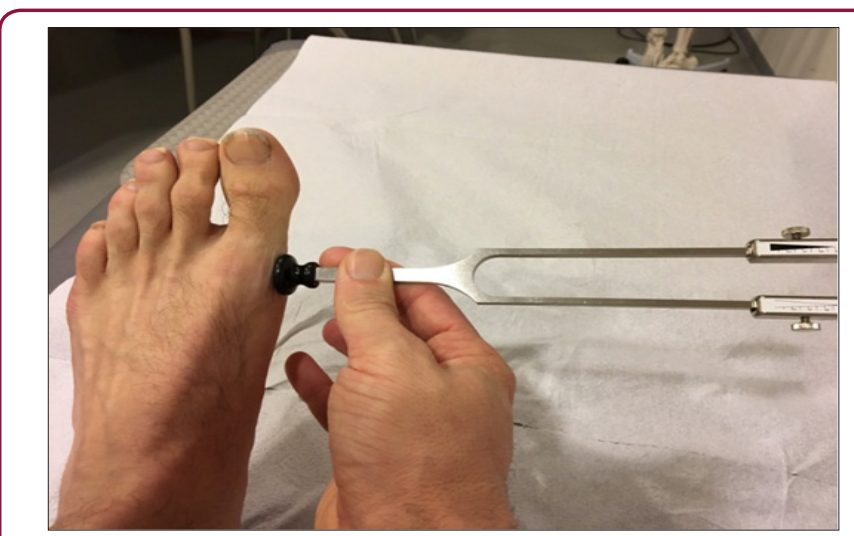

Figure 1: Tuning fork to detect loss of vibration in Charcot feet.

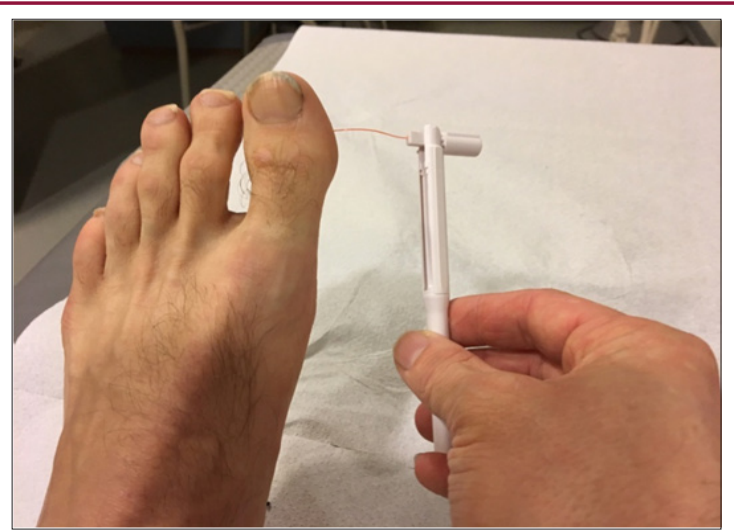

Figure 2: Loss of superficial sensation can be detected with a Semmes-Weinstein-Monofilament.

It is important to state that CN itself is a non-infectious disease. Even though secondary infections often are seen due to ulcerations or skin lesions. Autonomous neuropathy causing dry skin leads to unrecognized skin lesion and lets bacteria enter the foot. Most important is diagnosing polyneuropathy as soon as possible. Loss of sensation can be easily and cost effective examined using simple tools such as a tuning fork and a Semmes-Weinstein-Monofilament (Figures 1 \& 2). Pain at night, especially paraesthesia with "burning feet" or hypaesthesia, is often reported by patients. Unfortunately, still $\mathrm{CN}$ is sometimes recognized only after the first ulcerations appear. Sanders classified Charcot feet anatomically in 5 types: Type I affecting the metatarsophalangeal joints, type II the Lisfranc joint line, type III the Charcot joint line, type IV the ankle joint and type $\mathrm{V}$ the Calcaneus, in nearly all cases more than one type is affected in one patient.

\section{Imaging}

On the basis of X-ray findings Eichenholtz described three stages of $\mathrm{CN}$ : stage 1 (bone dissolution with destruction and disintegration of bone), stage 2 (coalescence or consolidation), and stage 3 (condensation or remodeling) [7]. The problem is that once radiologic signs can be seen, fractures and irreparable damage has already happened to foot. Classen and colleagues recognized that clinical symptoms regularly precede the X-ray signs of Eichenholtz stage 1 by several weeks, while scintigraphy bone abnormalities are detected [8]. This led to introduce Charcot foot stage 0 to the conventional classification by MR imaging $[9,10]$. Recently, Chantelau et al. proposed a complete new classification based an MRI [11]. Two severity grades are proposed according to the presence of cortical fracture and two stages (active/inactive) for inflammation signs. Senk et al. showed microfractures in early stages of $\mathrm{CN}$ of the foot in micro-CT [12]. Scintigraphy and ultrasound have also been used for imaging but there is no classification or typical signs for CN defined [12]. Using a PET-CT scan to find early inflammation in CN of the foot has been proposed by Ruttolo et al. [13].

\section{Laboratory Testing}

There are no specific markers in blood samples for CN. White blood cell count, sedation rate and CRP usually are not elevated unless there is a secondary infection. So, blood samples are most important to detect infection but not for diagnosing CN [14].

\section{Histopathology}

So far there have not been specific markers or a score existing to detect $\mathrm{CN}$ in bone or tissue samples in pathology. Therefore, diagnosing $\mathrm{CN}$ by taking intra operative samples still can lead to wrong results. At the moment the histopathological diagnosis is based on a semi quantitative analysis. A defined scoring system for instance as it had been developed for osteomyelitis, HOES, Histopathological Osteomyelitis Evaluation Score would be desirable for $\mathrm{CN}$ including all the inflammatory and non inflammatory alterations of this complex joint lesion [15]. In most recent research changes in the mRNA expression of collagens could be shown in intra-operative samples of Charcot feet. For the first time a morpholical correlate could be shown for the clinical and radiological well known typical changes in bone and capsula in $\mathrm{CN}$ of the foot [16].

Five collagen subtypes were specifically noted to be significantly over-expressed, notably Types II, IV, IX, XI, and XVII. In pooled bone RNA samples collagen XVII A1 was up-regulated by $52.5 \mathrm{x}$, 
collagen VI A6 by $6.3 \mathrm{x}$, and collagen VI A5 by 5.9x from patients with CN compared to controls. In joint capsule, collagen II A1 was up-regulated in CN by $122.4 \mathrm{x}$, collagen XI A2 by $9.5 \mathrm{x}$, collagen XIX A1 by $6.7 x$, and collagen XXIIA1 by $5.4 x$. A distinct pattern of overexpression of collagen mRNA subtypes was observed in CN. These observations provide insight into the molecular pathogenesis of $\mathrm{CN}$ and may serve as a molecular and cellular biomarker signature with potential use for early diagnosis of CN [16].

\section{Discussion}

Though important advances have been made especially in imaging, in clinical practice there is no reliable, specific and useful test for $\mathrm{CN}$. The pathological mechanism of $\mathrm{CN}$ has still not been understood and therefore there is no treatment for this specific inflammatory disease. X-rays are recommended for the first examination, the authors suggest $x$-ray with weight-bearing dorso-plantar, lateral and ankle anterior-posterior and immediate testing for polyneuropathy using simple tools as a tuning fork and Semmes-Weinstein-Monofilament [3]. If the $x$-Ray is negative MRI or nuclear imaging can be performed especially if infection is suspicioned [3]. Probing bone has been shown to have a high sensitivity for osteomyelitis [17]. One advance seems to be to improve and standardize MRI imaging. But even though, it seems to be possible to detect early stages of $\mathrm{CN}$, there is no reliable data yet about specificity and sensitivity of these procedures.

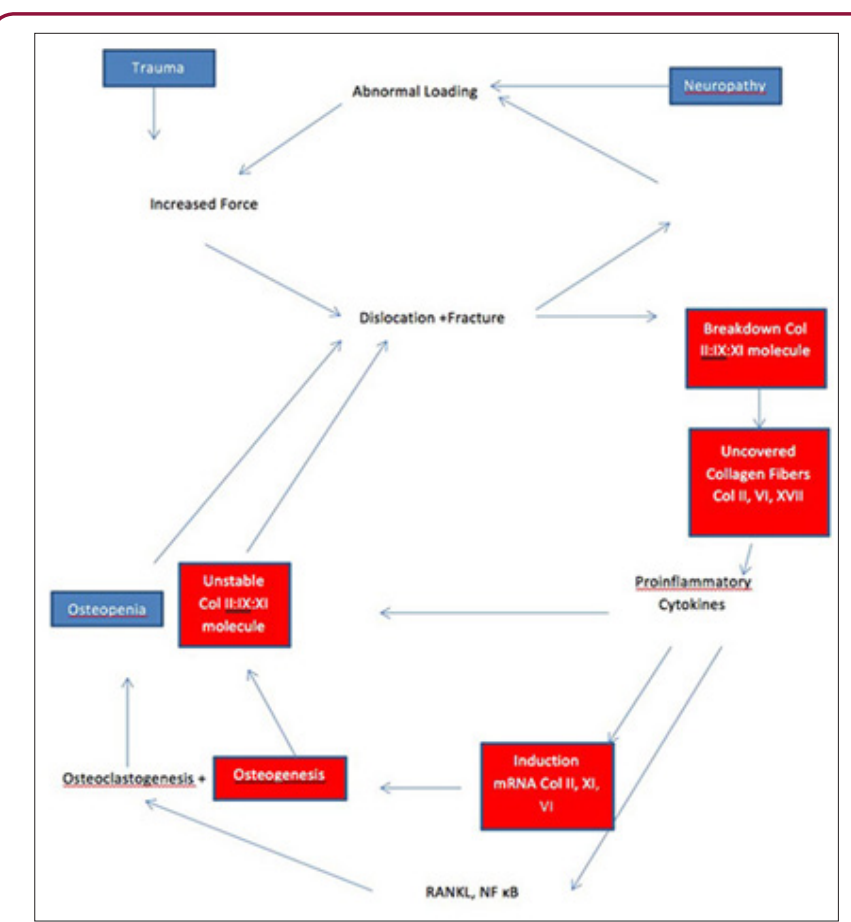

Figure 3: New hypothesis for the pathogenesis of $\mathrm{CN}$ : Double character of bone resorption and osteogenesis and the role of collagens in the vicious circle of inflammation.

Note: a. Red: The role of collagens and collagen breakdown; b. Blue: Original scheme by Jeffcoate of 2005 .

Another problem is that MRI is not available everywhere, it is expensive and it can take weeks to months to be performed. If a patient is presented for the first time, it would be necessary to detect $\mathrm{CN}$ as soon as possible to start for example off-loading e.g. using a total contact cast which has been proved to prevent $\mathrm{CN}$ from causing further damage. PET-CT probably will stay more a research approach for these reasons and seems not to be practical for the most of the patients. It remains difficult to definitely diagnose CN especially in early stages before major bone alterations even though simple and cost-effective clinical testing and examination of the patient can lead fast to the diagnosis of CN. Recent studies showed alterations of the mRNA expression of collagens in intra operative taken samples of Charcot feet (Figure 3) [16].

Proposed "vicious" inflammatory double cycle of $\mathrm{CN}$ and the critical role of collagens. Due to neuropathy which is seen in all patients with $\mathrm{CN}$ an abnormal gait and elevated peak pressure meet loose of the fat padding especially in the fore and middle foot. Unrecognized repetitive (micro-) trauma cause cortical fractures and triggers a pathological inflammation cascade through damaged, denatured or otherwise modified collagen II, VI and XVII fibers. This could lead to excessive, irregular and imbalanced recruitment of both osteoclasts and osteoblasts. The massive expression of collagen II:IX:XI heteropolymers missing the essential cross-linking of collagen IX results in breakdown of unstable heteropolymers, further driving the inflammatory cycle [16]. The role of mRNA expression changes in Charcot feet could suggest that $\mathrm{CN}$ may be further characterized, and possibly staged, by determining expression of collagen subtypes.

This may serve as a valuable diagnostic and research tool. As the observed changes in collagen mRNA species appear to be characteristic for $\mathrm{CN}$, these may serve as a $\mathrm{CN}$ gene expression signature. Ex vivo analysis of this $\mathrm{CN}$ signature may have important clinical implications with regard to diagnosis, staging, and future therapies of this disease. This finding was the first study, to the knowledge of the authors, with in vivo samples to show the role of collagens in $\mathrm{CN}$ and the first study with in vivo samples supporting the inflammation theory of Jeffcoate of 2005. These results could be a new approach and possible use for clinical tests, while valid tests for $\mathrm{CN}$ are still missing. But more research with more samples is necessary, and the hypothesis for the inflammation vicious cycle should be controlled in new studies [16,17].

Therefore it is essential to do more basic research and find the correlates of $\mathrm{CN}$ and its proposed inflammation mechanism. We need to find out, how this inflammation is triggered, which cytokines are involved and play key roles in this inflammation cascade. Further, it is important to find the histopathological correlate for the wellknown alterations in bone and soft tissue. Then there would be a possibility for reliable test to diagnose with a high specificity and sensitivity $\mathrm{CN}$ and to target specific cytokines and or surfaces to stop the destruction as in other diseases e.g. rheumatoid arthritis new drugs have changed the treatment profoundly.

\section{Conclusion}

It is essential to diagnose Charcot Neuropathy as most severe complication of diabetic feet in its early stages as soon as possible. Unfortunately there is still no reliable test, even though MRI imaging has improved to detect early stages of CN. Recent studies showed for the first time changes in the mRNA expression of collagens and 
this might be a morphological correlate for the inflammatory theory of Jeffcoate. These new findings might be valuable to create new histopathological test to detect $\mathrm{CN}$ in early stages. More research in this field is necessary.

\section{References}

1. Jeffcoate WJ, Game F, Cavanagh PR (2005) The role of proinflammatory cytokines in the cause of neuropathic osteoarthropathy (acute Charcot foot) in diabetes. The Lancet 366(9502): 2058-2061.

2. Lavery LA, Armstrong DG, Wunderlich RP, Tredwell J, Boulton AJM (2003) Diabetic Foot Syndrome Evaluating the prevalence and incidence of foot pathology in Mexican Americans and non-Hispanic whites from a diabetes disease management cohort. Diabetes Care [Internet]. Am Diabetes Assoc 26(5):1435-1438.

3. Rogers LC, Frykberg RG, Armstrong DG, Boulton AJ, Edmonds M, et al (2011) The Charcot foot in diabetes. J Am Podiatr Med Assoc 34(9): 2123-2129.

4. Wetz HH (1997) Orthopedic surgery treatment of diabetic neuropathic osteoarthropathy. Z Orthop Ihre Grenzgeb 135(4): 20-22.

5. Illgner U, Van Netten J, Droste C, Meiners T, Postema K, et al (2014) Diabetic Charcot Neuroarthropathy of the Hand: Clinical Course, Diagnosis, and Treatment Options. Diabetes Care 37 (5): 910-992.

6. Illgner U, Van Netten J, Droste C, Postema K, Meiners T, et al. (2014) Diabetic charcot neuroarthropathy of the knee: conservative treatment options as alternatives to surgery: case reports of three patients. Diabetes Care 37(6): 129-130.

7. Eichenholtz SN (1966) Charcot Joints. With a foreword by Philip D Watson, Springfield, Charles C Thomas Publisher, Illinois, USA.

8. Classen JN, Rolley RT, Carneiro R, Martire JR (1976) Management of foot conditions of the diabetic patient. Am Surg 42(2): 81-88.
9. Moore TE, Yuh WTC, Kathol MH, El Khoury GY, Corson JD (1991) Abnormalities of the foot in patients with diabetes mellitus: findings on MR imaging. AJR 157: 813-816.

10. Chantelau E, Richter A, Schmidt Grigoriadis P, Scherbaum WA (2006) The diabetic charcot foot: MRI discloses bone stress injury as trigger mechanism of neuroarthropathy. Exp Clin Endocrinol Diabetes 114(3): 118-123.

11. Chantelau EA, Grützner G (2014) Is the Eichenholtz classification still valid for the diabetic Charcot foot? Swiss Med Wkly 144: 13948.

12. Senck S, Plank B, Kastner F, Ramadani F, Trieb K, et al. (2015) Visualisierung lokaler kortikaler Defekte im Charcot-Fuß mittels Mikrocomputertomographie. Orthopaede 44(1): 8-13.

13. Ruotolo V, Di Pietro B, Giurato L, Masala S, Meloni M, et al. (2013) A New Natural History of Charcot Foot: Clinical Evolution and Final Outcome of Stage 0 Charcot Neuroarthropathy in a Tertiary Referral Diabetic Foot Clinic. Clin Nucl Med 38(7): 506-509.

14. Illgner U, Podella M, Rümmler M, Wühr J, Büsch HG, et al. (2009) Reconstructive surgery for Charcot foot. Long-term 5-year outcome. Orthopäde 38(12): 1180-1186.

15. Tiemann A, Hofmann GO, Krukemeyer MG, Krenn V, Langwald S (2014) Histopathological Osteomyelitis Evaluation Score (HOES) - an innovative approach to histopathological diagnostics and scoring of osteomyelitis. GMS Interdiscip Plast Reconstr Surg DGPW 3: 8.

16. Illgner U, Armstrong DG, Budny T, Brunner G, Slepian, M, et al. (2017) Collagen subtype mRNA over-expression in diabetic charcot neuroarthropathy: potential as pathogenic contributors and molecular signature. The Journal of Diabetic Foot Complications 9(1): 1-7.

17. Grayson ML, Gibbons GW, Balogh K, Levin E, Karchmer AW (1995) Probing to Bone in Infected Pedal Ulcers A Clinical Sign of Underlying Osteomyelitis in Diabetic Patients. JAMA 273 (9): 721-723. (c) (i) This work is licensed under Creative Submission Link: http://biomedres.us/submit-manuscript.php

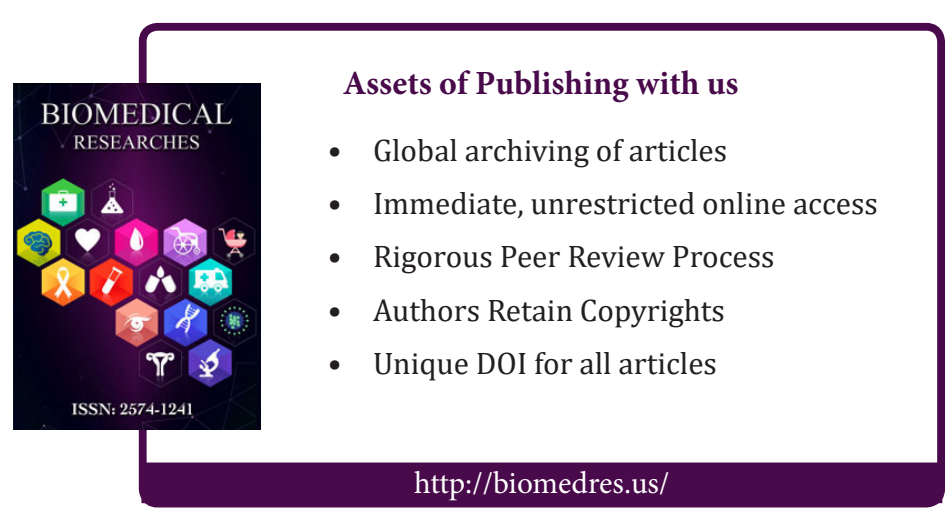

